\title{
Os documentos textuais e as fontes do conhecimento histórico ${ }^{1}$
}

Silvia Hunold Lara*

Resumo:0 artigo explora as possibilidades de trabalho com fontes textuais, utilizando como exemplo uma crônica escrita em 1678 que narra o acordo de paz firmado entre $G$ angazumbae o governo da capitania de Pernambuco.

Palavras-chave: Fontes históricas. D ocumentação textual. E scravidão. Palmares

Q ual o estatuto das fontes escritas na pesquisa histórica? A pergunta evoca um tema vasto e complexo e não tenho pretensão alguma de esgotar o assunto. Ao contrário: exploro aqui apenas alguns de seus aspectos e ofereço uma reflexão baseada no modo como tenho procurado tirar proveito de debates recentes sobre a relação entre o historiador e suas fontes em minha pesquisa sobre os "negros levantados do Palmar". Como se sabe, aqueles homens e mulheres que se amocambaram na região sul da capitania de Pernambuco ao longo do século XVII não sabiam ler e escrever e não há fontes textuais produzidas diretamente por eles. Por isso, o exemplo que utilizo permite acrescentar certa dose de "tempero" à discussão e talvez orientar o debate para aspectos de interesse da história social.

\footnotetext{
${ }^{*}$ Doutora em História pela USP. Professora Livre-Docente da Universidade Estadual de Campinas - UNICAMP. E-mail: shlara@ unicamp.br
} 
U m bom ponto de partida para abordar o tema é reconhecer a diferença entre fontes e documentos. 0 historiador tem à sua disposição um número limitado de textos e, para fazer história, precisa inventar suas fontes. Claro está que não se trata de criar, mas sim de inventar fontes: interrogar os textos de tal modo que sejam capazes de fornecer informações sobre as ações humanas no passado. U so o termo propositadamente, a fim de chamar a atenção para o fato de que o historiador não produz os documentos que utiliza, e jamais pode simplesmente recorrer a todos os textos escritos no passado. Para fazer história, é preciso selecionar alguns deles e transformálos em fontes de informação histórica. N ão se trata apenas de afirmar que os documentos dependem dos historiadores para se tornarem fontes, mas que há um processo de transformação que é fundamental para o próprio exercício do ofício do historiador. D esse processo, depende a qualidade da história que produzimos.

Com isso, tocamos em um tema clássico: os documentos não existem para registrar a história. Essa ilusão do século XIX, que deixamos para trás, muitas vezes, ainda ronda nossas pesquisas e teima em se fazer presente. Ao longo de suas vidas (individuais ou coletivas), homens e mulheres produziram textos diversos - do modo como achavam que deveriam ser escritos, por motivos e com fins os mais variados, que foram guardados ou descartados segundo critérios que faziam sentido para eles e, depois, para os profissionais responsáveis por sua preservação. $\mathrm{N}$ ão pretendo explorar aqui a multiplicidade de questões envolvidas na produção e no descarte de textos operados ao longo do tempo. Basta observar que tais registros geralmente chamados de documentos por arquivistas e historiadores - constituem o universo no qual os historiadores escoIhem suas fontes de informação sobre o passado. $N$ ão fosse a força do verbo "inventar", usado no parágrafo anterior, talvez, o que foi dito acima poderia ser tomado como uma obviedade. Vou tentar mostrar que não.

10 processo de transformação dos textos em fontes depende do que os historiadores querem saber sobre o passado. Conforme 
as perguntas que lhes são feitas, os documentos que sobreviveram até hoje podem se mostrar mais ou menos generosos. Claro está que não se pode fazer qualquer pergunta aos textos que encontramos nos arquivos. Q uando queremos saber coisas que não estão explicitamente registradas por eles, ou que não estão ligadas às motivações que deram origem aos escritos, temos que recorrer a estratégias para obter informações - inventar modos e meios de retirar dados e obter respostas para nossas perguntas - e, portanto, inventar fontes.

Há muitos anos, E ric Hobsbawm já havia comentado que essa questão se tornava particularmente sensível para os que estudam os movimentos sociais (ou populares) - a respeito dos quais não há fontes diretas:

Em muitos casos, o historiador dos movimentos populares descobre apenas o que está procurando, não o que já está esperando por ele. Muitas fontes para a história dos movimentos populares apenas foram reconhecidas como tais porque alguém fez uma pergunta e depois sondou desesperadamente em busca de alguma maneira - qualquer maneira - de respondê-la. (H O BSBAWM , [1988] 1998, p. 220).

Estas observações dizem respeito, num primeiro momento, ao conteúdo dos textos produzidos no passado. E sse é o modo mais comum de lidarmos com as fontes. Se alguém quer saber algo sobre os mocambos instalados nas serras ao sul de Pernambuco, por exemplo, a primeira coisa a fazer é coletar os textos produzidos no século XVII que falam sobre eles. A o examiná-los, toma-se o cuidado de saber quem os escreveu: no caso, foram geralmente militares encarregados das expedições punitivas ou governadores que queriam contar as lutas empreendidas ou se vangloriar das vitórias alcançadas. E m seguida, as várias informações que fornecem são cruzadas, combinadas e ajustadas de modo a formar um quadro das características daqueles mocambos e dos eventos a eles relacionados. Foi assim que a maior parte da bibliografia procedeu para construir a história de Palmares. 0 método, embora usual, não deixa de ser problemático. 
Há duas críticas principais que já foram feitas em relação a esse procedimento. A primeira diz respeito à necessidade de levar em conta, na análise, a "miopia" cultural dos portugueses e holandeses, incapazes de compreender a cultura daqueles fugitivos. É preciso, então, fazer a crítica do etnocentrismo, verificar como as palavras usadas traduziram costumes, nomes e cargos centro-africanos, bem como prestar atenção às diferenças de ortografia e de transcrição na transmissão de um manuscrito para outro. ${ }^{2} 0$ alerta carrega, porém, a ilusão de que as eventuais distorções podem ser corrigidas desde que se recorra a bons instrumentos de apoio, como os conhecimentos produzidos pelas análises lingüísticas, históricas e antropológicas dos reinos do K ongo e Angola ou da África Centro-O cidental.

A segunda diz respeito à necessidade de aprofundar o conhecimento dos autores desses textos, conhecer o contexto em que foram produzidos, com a finalidade de superar aquilo que $D$ écio Freitas chamou de "falsificação ideológica" presente nos textos disponíveis sobre Palmares. Como vários outros, ele proclamou a necessidade de não se tomar "ao pé-da-letra tudo quanto está escrito nos documentos", pois eles contêm exageros, mentiras e invenções em função dos "interesses pessoais e sociais" de seus autores (FREITAS, 1985, p. 176). ${ }^{3}$ As palavras são fortes, mas traduzem bem a utopia de que os historiadores podem chegar a saber realmente 0 que aconteceu, a tocar a verdade escondida por trás das armadilhas presentes na documentação. A ilusão, aqui, é a de que são os documentos que inventam a história e a de que os historiadores são capazes de corrigir as "falsificações" e o que foi distorcido por essa "invenção".

2. Para criticar essa postura diante dos documentos e se contrapor a ela, outros historiadores têm insistido em mostrar os limites dos textos que costumamos ler nos arquivos. 0 s documentos são opacos, dizem eles: não nos dão acesso aos fatos do passado, mas apenas ao gesto da escrita que eles conservam e registram. A ssim, por exemplo, as palavras que compõem uma carta dirigida ao soberano português, escritas de acordo com regras específicas, que também 
têm uma história, falariam mais de seus autores e do modo como as comunicações eram operadas entre as autoridades coloniais e a Coroa do que sobre os acontecimentos de que tratam.

$\mathrm{N}$ as últimas décadas, várias discussões teóricas e metodológicas têm mostrado a necessidade de prestar atenção ao contexto institucional de produção de cada peça documental, às intenções do autor, aos termos empregados na descrição dos eventos e na qualificação das pessoas e às traduções lingüísticas e culturais operadas em cada texto. ${ }^{4}$ Todo um campo novo de indagações tem se aberto com 0 aprofundamento da análise dos recursos narrativos em ação nos documentos: cada vez mais se presta atenção aos procedimentos da construção dos textos, às condições da escritura, ao destino das peças textuais e ao modo como foram lidas na época em que foram produzidas. ${ }^{5}$

Algumas vezes, esses aspectos textuais acabam por ganhar tanta importância, que se fala mais deles do que dos movimentos sociais que queremos estudar. 0 s textos acabam se tornando o objeto mesmo da pesquisa - e assim abrem-se novas perspectivas para a história da leitura e das operações discursivas. Em casos extremos, 0 texto - ou o discurso, como querem al guns - torna-se praticamente 0 único território da pesquisa histórica. No afã de evitar a armadilha de supor que os textos são transparentes - ou de que se pode corrigir suas "distorções" - acaba-se por excluir a possibilidade de pensar (e fazer) a história da escravidão.

3. N ão vou avançar muito na análise desse contraponto que apresento aqui de forma propositadamente resumida e esquemática, apesar de não querer partilhar das simplificações que, muitas vezes, freqüentam os debates atuais sobre esse tema. Por ora, todavia, creio ser suficiente afirmar que discordo tanto de uma posição quanto de outra.

Para me explicar melhor, volto a minhas palavras iniciais: "ao longo de suas vidas, homens e mulheres produziram textos diversos - do modo como achavam que deveriam ser escritos, por motivos e com fins os mais variados". Pois bem: isso significa dizer que a leitura 
não deve buscar apenas o que foi escrito, mas também como foi escrito, por que foi escrito e como aquele texto circulou e foi guardado. Todos esses aspectos são fontes de informação para os historiadores. Para além de seu "conteúdo", um texto também possui elementos materiais que, juntamente com o gesto que lhe deu origem, preci-

N sam ser levados em conta na análise. I sso não implica ter que mudar de objeto, ou ter que deixar de fazer história social. Ao contrário: ao levarmos em consideração todos esses componentes de um documento textual, ampliam-se as possibilidades de conhecer e compreender as ações humanas no passado. Mais ainda, sem a análise simultânea deles, perdemos informações e não conseguimos transformá-los em fontes históricas.

No caso de Palmares, como observei, não há documentos produzidos pelos palmarinos e a maior parte dos textos disponíveis foi escrita por autoridades engajadas na administração colonial. Por isso mesmo, atentar para as circunstâncias em que os textos foram escritos torna-se ainda mais importante, sobretudo se as perguntas feitas a eles pretendem obter informações sobre os habitantes dos mocambos. Os registros disponíveis documentam também as relaçōes nas quais Palmares e seus habitantes estavam inseridos.

Alguns historiadores alertam ainda que, além do gesto da escrita, da produção do texto e do que eles registram, é preciso pensar também no longo caminho que fez com que aquele texto chegasse até os dias de hoje. De fato, como afirmei anteriormente, "depois de escritos, por motivos e com fins variados, os textos são guardados ou descartados segundo critérios que faziam sentido para os homens e mulheres do passado e, depois deles, para os profissionais responsáveis por sua preservação". N enhum pesquisador na área da história pode dispor de todos os textos produzidos no passado. Mesmo que isso porventura acontecesse, nenhuma pesquisa poderia ser feita com todos eles - todo trabalho de investigação implica separar e selecionar os documentos capazes de oferecer respostas a perguntas específicas. A nalisar quais textos foram utilizados pelos historiadores para tratar de certos eventos - e como eles os interrogaram - é 
parte importante da crítica historiográfica que, no entanto, nem sempre é realizada. E mbora interessante, o tema é vasto e sou obrigada a deixá-lo de lado para retomar meu argumento.

4. Vejamos um exemplo rápido, mas eloqüente, que retiro de minha própria pesquisa. Um dos textos mais usados pela bibliografia sobre Palmares é uma crônica escrita em 1678 que conta a história de Palmares, das guerras feitas por Fernão Carrilho por ordem do governador de Pernambuco, dom Pedro de Almeida, e do acordo de paz que acabava de ser firmado com $G$ angazumba. E sse documento é conhecido pelo título que lhe atribuiu o conselheiro D rummond, responsável por sua primeira divulgação nas páginas da Revista do Instituto H istórico e Geográfico Brasileiro, em 1859: "Relação das guerras feitas aos Palmares de Pernambuco no tempo do governador dom Pedro de A Imeida de 1675 a 1678". A publicação não traz qualquer referência sobre 0 original consultado pelo conselheiro, e o texto tem sido utilizado como referência documental básica por quase todos os historiadores que lidam com a história de Palmares ou editam coletâneas de documentos referentes a ela.

$\mathrm{O}$ conselheiro D rummond, sócio do Instituto $\mathrm{H}$ istórico e G eográfico Brasileiro, atendia a uma das incumbências dessa instituição que, entre outras coisas, visava "coligir e preparar os materiais necessários para a história e geografia do Brasil". 0 tema já havia sido objeto de discussão numa das sessões do Instituto, na qual se havia recorrido ao caso de Palmares para exemplificar como a consulta a novos documentos, obtidos em viagens científicas, poderia dirimir dúvidas até então insolúveis com os escritos disponíveis. ${ }^{6}$ Como muitos outros sócios, D rummond era também ministro de Estado, e aproveitou suas viagens diplomáticas ao exterior para visitar diversos arquivos, enviando de lá cópias de documentos ao cônego Januário da Cunha Barbosa, secretário da instituição, algumas das quais para serem publicadas na revista (ver, por exemplo, DRUMMOND, 1844).

D esde que apareceu nas páginas daquele periódico, a "Relação das guerras" tornou-se o documento mais lido, analisado, citado e 
discutido pelos que se interessam pela história de Palmares. Todos, sem exceção, adotaram o procedimento padrão de retirar desse texto as informações sobre a vida nos mocambos ou sobre as campanhas realizadas contra os palmarinos. 0 que ali vai dito foi sempre o que chamou a atenção dos historiadores. 0 conteúdo daquela crônica, preservado pela versão impressa publicada mais de 180 anos depois de ela ter sido escrita, foi utilizado sem problemas, criticando-se eventualmente 0 viés laudatório do texto, seu exagero em alguns números ou o viés etnocêntrico na caracterização dos mocambos.

E $m$ 1876, Pedro Paulino da Fonseca, outro membro do Instituto $\mathrm{H}$ istórico e $\mathrm{G}$ eográfico Brasileiro, publicou uma versão dessa crônica, dando ao seu texto outro título: "M emória dos feitos que se deram durante os primeiros anos de guerra com os negros quilombolas dos Palmares, seu destroço e paz aceita em junho de 1678" (FO N SE CA, 1876, p. 293-322). N esse caso, porém, trata-se de uma recriação do texto escrito em 1678, não de uma transcrição - fato que é explicitamente reconhecido pelo autor, que indica tomar por base um manuscrito existente na Biblioteca Pública de É vora (FO N SE CA , 1876, p. 321). A comparação entre o manuscrito de É vora e o texto de Fonseca confirma que ele não só acrescentou dados ealterou frases, como completou o texto, já que o manuscrito de É vora não possui título e está incompleto. ${ }^{7}$ A pesar de acompanhar de perto o documento, Fonseca é aqui, inequivocamente, 0 autor do texto. N ão obstante, é fácil encontrar na bibliografia sobre Palmares quem use o texto publicado em 1859 pelo conselheiro D rummond e 0 de Paulino da Fonseca como se fossem fontes equivalentes ou de mesma natureza.

É interessante observar que o documento guardado pela Biblioteca Pública de É vora nunca chegou a ser publicado. D e certa maneira, talvez porque interessados apenas em seu conteúdo, os historiadores usaram em seu lugar a recriação publicada por Pedro Paulino daFonseca. 0 manuscrito deÉ vora também não corresponde ao texto impresso em 1859 pelo conselheiro D rummond. N este caso, porém, a falta de referências sobre o original transcrito por ele pode 
ser parcialmente compensada por menções, feitas por outros autores, em especial em artigos da Revista do Instituto A cheologico e G eographico A lagoano, de que o original estaria na Torre do Tombo e que uma cópia teria sido doada à Biblioteca $\mathrm{N}$ acional no Rio de Janeiro.

A cópia existente na Biblioteca $\mathrm{N}$ acional, com letra do século $X I X$, indica ter sido feita a partir de um texto que estaria no "tomo primeiro de Papéis Velhos de folhas cento e quarenta e duas, até cento e quarenta e oito, existente no Armário de Manuscritos do Real A rquivo da Torre do Tombo". E ssa cópia, contudo, tem outro título: "D escripção com notícias importantes do interior de Pernambuco como rio de São Francisco, Porto Calvo, Palmares, cabo de Santo A gostinho, as distâncias de huns lugares aos outros etcetera, das partes mais férteis; costumes dos Palmares (negros) e modo como vivem seu regimen, dos damnos que recebem os portugueses d'eles: enfim o estado em que foram achados os Palmares, sobre a partida de Pero de A Imeida contra os ditos, e a descripção do que se fez para a ruína, em que vierão a cair os Palmares". A colação dos textos indica que essa cópia - ou o original da Torre do Tombo - deve ter sido a fonte da transcrição publicada pelo conselheiro D rummond em 1859. 0 mistério aumenta quando, apesar de vários esforços, consultas e tentativas - minhas e de vários colegas e técnicos da Torre do Tombo - a tal manuscrito até hoje não pôde ser localizado naquele acervo. ${ }^{8}$

Para encurtar a história: conheço, até agora, sete textos diferentes dessa crônica:

- o manuscrito de É vora, cuja letra é do século XVII;

- a cópia existente na Torre do Tombo, que também não pôde ser até agora localizada;

- duas versões delas publicadas por D écio F reitas, que afirma transcrever cópias guardadas pelo A rquivo $\mathrm{H}$ istórico U Itramarino e pela Biblioteca N acional de Lisboa (FRE ITAS, 2004, p. 19-50) que, apesar de vários esforços e tentativas, não foram localizadas nesses arquivos;

- a cópia (do século XIX) da Biblioteca N acional; 
Os documentos textuais e as fontes do conhecimento histórico

- a versão publicada pelo conselheiro D rummond em 1859;

- a versão recriada por Pedro Paulino da Fonseca, publicada em $1879 .{ }^{9}$

$\mathrm{N}$ a busca por esses textos, às vezes angustiante, às vezes divertida, tenho sido auxiliada por amigos e colegas de profissão, por arquivistas e bibliotecários. ${ }^{10}$ Por que tanta insistência em localizar e cotejar os "originais" de um documento cujo "conteúdo" é, basicamente, o mesmo? A lém do fato de nunca ter sido realizada, essa investigação - com características muitas vezes detetivescas - tem pelo menos dois objetivos. Primeiro, o confronto entre as várias versões permite verificar - por meio do exame das letras e dos fundos nos quais foram preservados - os caminhos da circulação daquela crônica anônima, que tudo indica ter sido escrita em 1678. Segundo, a comparação entre os originais e os textos que foram publicados no século XIX fornece elementos para entender como os institutos históricos coletaram documentos referentes ao período colonial e, ao publicá-los, terminaram por fixar caminhos interpretativos que continuam a ser seguidos - às vezes ingenuamente até hoje. Vários estudiosos têm analisado as características da história produzida pelos institutos, mas poucos já se perguntaram sobre 0 processo de construção de um cor pus documental empreendido por eles. E sse é mais um tema interessantíssimo a que sou obrigada a deixar de lado para seguir a análise do exemplo escolhido.

Voltemos, pois, à crônica de 1678.

D eterminar qual a matriz - ou o texto que estaria mais próximo de sêlo - e quais as cópias é condição necessária para um estudo mais aprofundado do documento, de modo a obter dele maior número de informações. M esmo que não se possa datar ainda os textos guardados pela Torre do Tombo, A rquivo H istórico U Itramarino e Biblioteca $\mathrm{N}$ acional de Lisboa, é bastante plausível que tenham existido pelo menos duas cópias dessa crônica no século XVII: a que se encontra na Torre do Tombo (ainda não localizada) e a existente em É vora, cuja letra é do século XVII. A existência de cópias em arquivos que guardam documentos da Corte portuguesa e dos 
órgãos encarregados da administração ultramarina indica que a notícia da vitória obtida em Pernambuco em 1678 teve alguma circulação em Portugal, indo além dos circuitos burocráticos do Conselho Ultramarino.

0 texto é anônimo, mas vários elementos indicam ter sido escrito em Pernambuco, por ordem de dom Pedro de Almeida ou por alguém próximo a ele, entre junho e agosto de 1678. 0 governador havia enfrentado problemas desde 0 início: sua nomeação causara constrangimentos no Conselho U Itramarino ${ }^{11} \mathrm{e}$, em Pernambuco, entrara em conflito com importantes lideranças políticas e militares da região (ver, por exemplo, MELL0, 2000, p. 424-427). E m 1676, o Conselho U Itramarino chegou a ordenar investigações contra ele, por conta de acusações feitas por algumas câmaras pernambucanas. ${ }^{12}$ É bem verdade que também tinha aliados, já que se pode encontrar uma carta da câmara de 0 linda e outras do provedor da Fazenda de Pernambuco que elogiam sua administração. ${ }^{13} \mathrm{~N}$ omeado em agosto de 1677, Aires de Souza de Castro, o novo governador já havia chegado e tomara posse em abril de 1678. E m junho, dom Pedro de Almeida se preparava para voltar a Lisboa e certamente teria dificuldades diante da tradicional "residência" sobre seu governo. ${ }^{14}$ Sua carreira política estava em perigo e aquele texto era uma peça importante nesse jogo de forças. E is aí o famoso "contexto": a situação na qual o texto foi produzido e circulou.

U m exame da própria narrativa reforça essa hipótese - e aqui, uso o manuscrito de É vora, já que ainda não consegui localizar o documento guardado pela Torre do Tombo. Elementos do texto indicam que foi escrito para uma audiência portuguesa, com 0 objetivo de enaltecer a figura do governador. A vitória contra Palmares e 0 acordo de paz celebrado entre $G$ angazumba e as autoridades de Pernambuco são descritos como um trunfo político. Pedro deA Imeida é a figura central, capaz de manejar a situação, ordenar expedições e garantir uma vitória sobre um inimigo tão importante quanto os holandeses. A descrição dos mocambos tem uma função específica: mostrar como Palmares era poderoso e perigoso. 0 acordo de paz 
não era uma simples vitória contra escravos fugidos, mas a "feliz restauração destas capitanias [de Pernambuco]" (RELAÇÃ O, 1678, fl. 52v). 0 termo "restauração" é significativo: foi empregado para descrever a guerra contra a E spanha em 1640, a expulsão dos holandeses de Angola, em 1648, e de Pernambuco, em 1654. A vitória $\infty$ sobre Palmares era, portanto, um feito militar e político comparável a esses outros.

N essa narrativa, a figura oposta a Pedro de A Imeida é $G$ angazumba: um "rei", que "tem palácio capaz da sua família, que é grande, [e] é assistido de todas as guardas e oficiais que costumam ter as Casas Reais" (RELAÇÃ 0, 1678, fl. 51v). Palmares aparece caracterizado como um estado bem organizado do ponto de vista militar e político, com juízes e magistrados, e uma capela com imagens cristãs. Para vários autores, tais características seriam fruto do "etnocentrismo" ou de uma "inadequação" de linguagem. Creio, entretanto, que eles podem ser entendidos de pelo menos dois outros modos.

E m primeiro lugar, essa forma de descrever e caracterizar Palmares guarda semelhança com procedimentos adotados por outros textos do mesmo período - e aproveito para abordar aqui um segundo significado da palavra "contexto". Conforme já observou John Thornton (1981, p. 193-197), os textos escritos por portugueses e centro-africanos nos séculos XVI e XVII, durante o processo de ocupação da África Centro-O cidental, operavam com conceitos de soberania, nobreza e vassalagem que eram comuns às duas culturas. 0 fato de o mani ou ntotela, no K ongo, ou o ngola, no $\mathrm{N}$ dongo, terem sido chamados "reis" não era fruto de uma operação retórica, mas descrevia tanto as relações internas entre o rei do Congo e seus vassalos quanto entre eles e os portugueses. Sem me estender demasiadamente sobre 0 assunto, essa comparação permite concluir que os termos empregados pela crônica de 1678, ao invés de evidenciarem alguma "miopia", documentam uma forma de percepção e de avaliação política de Palmares que, no contexto seiscentista, atribuía aos mocambos qualidades similares àquelas 
encontradas pelos portugueses em suas relações com os sobas centroafricanos - com os quais era possível estabelecer pactos políticos, acordo diplomáticos, etc.

E m segundo lugar, a descrição se organiza de modo a demonstrar que Palmares tinha Fé, Lei e Rei. O s mocambos não apenas tinham "rei", mas também "ministros de Justiça, assim como de guerra"; e uma "capela, a que recorrem nos seus apertos", com imagens do menino Jesus, de N ossa Senhora da Conceição e de São Brás (RE LAÇÃ O, 1678, fls. 51v-52). Chamo a atenção, aqui, para a tríade pela qual os portugueses avaliavam o grau de "civilização" dos povos com os quais tinham contato. $\mathrm{N}$ a crônica de 1678, 0 tropo foi empregado em sentido inverso àqueleusado paradesqualificar os índios do Brasil. Vários textos portugueses escritos nos séculos XVI eXVII, como os de Pero de M agalhães G andavo ([1576] cap. 7), F rei $V$ icente do Salvador ([1627] 1889, p. 25), referem-se à falta das letras F, L, R entre os indígenas, para acentuar sua barbárie e justificar a necessidade de dominá-los e catequizá-los (ver FERRO N HA, 1991; LO UREIRO, 1991 e GIUCCI, 1993, cap. 5). Palmares, ao contrário, assim como os reinos e sobados na África Central, possuía um rei venerado e reconhecido por todos como senhor; magistrados e "todos os arremedos de qualquer República"; e seus habitantes não haviam perdido "o reconhecimento da I greja", com sua capela e um "a que chamam ganga" que os batiza e casa. (RE LAÇÃ O, 1678, fls. 51v-52). A ssim qualificado, constituía um E stado - e a vitória conseguida em 1678, bem como 0 acordo de paz com G angazumba tornavam-se feitos mais gloriosos e honrados.

E ssa forma de apreender e caracterizar Palmares aparece também nos outros textos do século XVII eXVIII, embora com algumas nuances - como a "Relação verdadeira da guerra que se fez aos negros levantados do Palmar em 1694" (O LIVEIRA, 2005), ou os famosos parágrafos de Rocha Pita ([1730] 1976, p. 213-219) sobre a derrota final dos mocambos. Escritos para audiências portuguesas ligadas à administração colonial, esses textos operam oposições cons-truídas com intenções claramente políticas: na crônica 
Os documentos textuais e as fontes do conhecimento histórico

de 1678, os protagonistas são dom Pedro de A Imeida e $G$ angazumba; na "Relação verdadeira", são Bernardo V ieira de M elo e Zumbi; na $\mathrm{H}$ istória da A mérica portuguesa, M elo de Castro e Zumbi. N o primeiro caso, Palmares é descrito como um estado, com fé (já que tem capela), lei (com juízes e magistrados) e um rei ( $G$ angazumba): um reino civilizado com o qual é possível negociar e estabelecer acordos. N os dois últimos, tais características também se fazem presentes, embora sejam as qualidades bélicas dos palmarinos, sua disciplina e poder de fogo a serem enfatizados, e se dê destaque ao comando heróico de Z umbi. Tais procedimentos narrativos operam no sentido de tornar ainda mais evidente os méritos de dom Pedro de A Imeida, Bernardo Vieira de M elo ou de Caetano de M elo de Castro e ainda mais gloriosa a vitória que obtiveram.

Tais características narrativas da crônica de 1678 constituem um fato tão importante quanto os eventos que ela descreve. Como os historiadores não querem apenas saber dos fatos, e sim entender por que e como eles aconteceram, cabe seguir adiante. U ma vez identificada o tópico de retórica que estrutura o texto, o passo seguinte é perguntar o que ela significa. A resposta pode ser encontrada justamente no modo como esse e outros textos análogos usam a menção a Palmares, seguindo essa retórica, ao serem escritos para um público português, numa situação de contendas políticas entre portugueses na metrópole ou na América. O u seja: é preciso partir do modo como esses textos foram escritos e das contendas políticas que levaram essas narrativas a dizerem o que dizem - do modo como dizem.

5. $E$ is o que não estava tão evidente em minha afirmação inicial de que "os documentos não foram escritos para serem registros históricos". Escrita de um jeito compreensível para os homens ligados à administração portuguesa, a crônica de 1678 visava fins bastante específicos. Saber se esse texto circulou e por quem e como foi lido não é, portanto, mero exercício de "crítica documental", assim como examinar suas práticas discursivas não é eleger a literatura em detrimento da história. Esses elementos permitem contextualizar 
e compreender o esforço feito para assinalar a existência, em Palmares, de um chefe político - um rei - com quem se podia negociar. Mais que isso: revelam que homens ligados à administração colonial portuguesa, no século XVII, puderam equiparar Palmares a um sobado centro-africano equalificar a negociação empreendida com $\mathrm{G}$ angazumba como equivalente aos acordos contemporâneos feitos em Á frica.

E stamos aqui, diante de uma novidade, sem dúvida. D iferentemente do caminho adotado pela maioria dos historiadores que tratam da história de Palmares, a equiparação não foi feita pela via das identidades culturais ou étnicas - mas pelo terreno da política. Tal constatação amplia as possibilidades de análise do tema, ao situar o acordo de 1678 no quadro maior das formas do exercício da dominação portuguesa no Ultramar.

A tríade Fé, Lei e Rei constitui uma chave interpretativa que se refere a um modo de ocupar terras e dominar gentes característico do processo colonizador português nos séculos XVI e XVII. N a A mérica, as terras eram ocupadas por povos que os portugueses consideravam não ter fé, lei e rei: para dominá-los foram organizadas missões e aldeamentos. Para os que resistiam, a guerra era justa. Para os que "desciam" para as aldeias, a educação e a catequese constituíam a base do bom governo sobre eles (ver, entre outros, A L ME IDA, 2003 e PO M PA, 2003). U ma vez convertidos ao cristianismo, seus líderes até podiam ser reconhecidos e receber títulos de nobreza (D UTRA, 1970). M as não eram considerados vassalos da Coroa nem tinham autonomia. ${ }^{15} \mathrm{~N}$ a Á frica, as terras eram ocupadas por povos que tinham fé, lei e rei: com eles, houve relações diplomáticas desde 0 início, e as negociações, tratados e acordos eram freqüentes. As linhagens e as relações políticas entre eles eram reconhecidas pelos portugueses, integradas mesmo ao modo como operavam para dominar o território africano e auferir suas riquezas. ${ }^{16}$

E $m$ 1678, dom Pedro de A Imeida pôde se orgulhar de ter finalmente "restaurado" Pernambuco depois ter vencido os negros dos Palmares e ter firmado com seu rei um acordo que levou centenas de pessoas a se deslocarem até a aldeia de Cucaú. A negociação da 
Os documentos textuais e as fontes do conhecimento histórico

paz foi feita de modo similar à relação que portugueses mantinham com os sobados centro-africanos. A o mesmo tempo, elas deram origem a uma aldeia, em terras concedidas por "mercê", onde os antigos moradores de Palmares teriam liberdade para viver e plantar, com padres para Ihes ensinar "a viver e morrer pela fé de Cristo", tendo os mesmos privilégios que os demais vassalos do rei, sem serem obrigados a "trabalhos particulares" ${ }^{17} \mathrm{~A} 0$ enfatizar as características políticas e militares de Palmares como um estado africano na Amé rica, a crônica de 1678 procurava justificar a opção pelo acordo de paz e caracterizá-lo como o coroamento de uma vitória militar como em África.

Só podemos chegar a essas conclusões se analisarmos ao mesmo tempo os eventos descritos por aquela crônica (seu "conteúdo"), as circunstâncias em que foi produzida, os procedimentos narrativos adotados por seu autor e como ela circulou e pôde ser lida e entendida no século XVII. Há, portanto, muitos fatos registrados em cada peça textual. Só assim aquele texto (e todas as suas versões) tornam-se fontes históricas - ou seja, permitem saber não "o que aconteceu", mas como e por que algo aconteceu - e, o que é mais importante, quais homens e mulheres estavam envolvidos naqueles eventos, por quais motivos e com que objetivos. Por isso, os textos não são meras representações nem simplesmente referem fatos do passado, mas mantêm múltiplas e complexas relações com diferentes ordens de eventos. Sem pretender estabelecer qualquer verdade sobre o passado e sem confundir o terreno história com o da teoria literária, esse caminho permite colocar os textos em perspectiva histórica.

Tratado como um soba africano em terras pernambucanas, $G$ angazumba pôde ser reconhecido como detendo um poder com o qual era possível fazer acordos, e contra o qual os potentados portugueses e coloniais podiam lutar com heroísmo. $\mathrm{N}$ em falsa nem verdadeira, mas historicamente situada, tal avaliação seiscentista sobre Palmares abre caminho para uma análise que pode oferecer novos elementos 
para compreender a história dos mocambos instalados nas serras ao sul de Pernambuco.

Por exemplo: se as relações entre os reinos africanos na África e entre eles e os portugueses ali estabelecidos puderam servir de parâmetro para o modo como as auto ridades coloniais lidaram com o sobado de Palmares na A mérica, não seria plausível pensar que isso acontecesse também com $G$ angazumba e seus companheiros? D ito de outro modo, se a experiência da dominação na África Central podia servir de parâmetro para os portugueses lidarem com os africanos do outro lado do A tlântico, isso não poderia ter acontecido também com os centro-africanos? A final, além de suas identidades, de sua cultura, os africanos também trouxeram, para essas terras americanas, uma larga experiêndia política. ${ }^{18}$ Se isso foi reconhecido pelas autoridades portuguesas e coloniais, não seria importante ser também conhecido pelos historiadores?

A pergunta leva a história de Palmares a ganhar dimensões bem mais amplas do que habitualmente Ihe tem atribuído a historiografia. D e todo o modo, não é minha intenção seguir adiante com essas reflexões, aqui. Posso concluir dizendo que, se essa experiência política dos negros do Palmar - profundamente centro-africana não pôde ser reconhecida pelos historiadores até hoje, talvez tenha sido porque a maioria deles se acostumou a ler os documentos escritos no século XVII "desavisadamente": sem verificar, por exemplo, se há uma ou mais versões daquela crônica além da que foi publicada pelo conselheiro $D$ rummond, ou com a certeza de que uma verdadeira teoria e um conhecimento mais amplo dos fatos seria condição suficiente para evitar as armadilhas da "falsidade ideológica". Como já mencionei, observar os elementos textuais daquele documento não significa permanecer apenas na literalidade dos textos. É a análise simultânea de todos esses elementos que permite transformar os textos em fontes - em fontes de conhecimento histórico. 
Os documentos textuais e as fontes do conhecimento histórico

E a história, ainda bem, é muito mais complexa do que podemos imaginar - ou inventar!

Textual documents and sources of historical knowledge

Abstract: This article explores the possibilities of work with textual sources, by using a chronic written in 1678, which narrates the agreement of peace between $G$ angazumba and the government of the captaincy of Pernambuco.

Keywords: $\mathrm{H}$ istorical Sources. Textual documents. Slavery. Palmares

\section{$\mathrm{N}$ otas}

${ }^{1}$ Texto apresentado na mesa-redonda sobre "Fontes E scritas" durante o IX E ncontro E stadual deH istória - AN PUH -RS - "Vestígios do passado. A história e suas fontes", em 15 dejulho de 2008. 0 tema foi abordado de forma a atender questões propostas pelos organizadores da mesa-redonda. M inha pesquisa sobrePalmares contacom o apoio de umaBolsade Produtividadeem Pesquisa do CN Pq efaz partede um projeto temático financiado pela FA PE SP. A gradeço aos colegas participantes da mesa-redonda e ao público do evento as questões e comentários feitos na ocasião. ${ }^{2}$ Robert N . A nderson (1996, p. 100-101) exprimeessa preocupação de modo exemplar, ao mencionar que os artistas e estudiosos de Palmares "têm reapropriado uma história registrada pelo inimigo que apresenta as seguintes dificuldades: (1) inescapável etnocentrismo, encarnado na linguagem, do europeu com respeito ao africano ou afro-americano; (2) a inadequação de uma língua para traduzir outra, especialmente quando as estruturas sociais referidas não têm equivalentes na cultura da língua tradutora; (3) os problemas ortográficos em render os nomes próprios ou as palavras intraduzíveis de uma língua para outra e (4) a possibilidade de transmissão fal ha de um manuscrito para outro".

${ }^{3}$ Ver também Freitas (2004, p. 13). A denúncia da "ideologia senhorial" presente em textos dos séculos XVII aXX ébastante freqüente na historiografia marxista sobre os quilombos. Vide, por exemplo, Moura (1990).

${ }^{4} D$ entre vários autores, destaco as contribuições diferenciadas de Robert $D$ arnton e Roger Chartier. Vide, entre outros, D arnton (1990) eChartier (1992).

${ }^{5}$ Para um balanço dos debates e principais temas abordados pela história da leitura, ver Belo (2002). Para a produção e a circulação dos manuscritos nos séculos XVI e XVII, videespecialmente Bouza (2001).

${ }^{6}$ Ver Pontes (1841). Segundo o desembargador Pontes, a tarefa deveria ser realizada no Brasil eem missões no exterior eeraimportantenão apenas para o conhecimento da história, mas também para dirimir contradições entre autores que tratavam de um 
Sílvia Hunold Lara

mesmo tema. Talvez por ser alagoano, Pontes tenha citado como exemplo anecessidade de esclarecer as divergências entre $G$ aspar Barleus, Brito F reiree RochaPita ao tratarem da "famosa história da povoação" de Palmares.

${ }^{7} \mathrm{~A}$ pesar da referência ao manuscrito deÉ vora, Fonseca não levou em conta o título que Ihe havia atribuído o bibliotecário J oaquim H eliodoro da Cunha Rivara (1850, to mo I, p. 144) ao elaborar o catálogo daquela instituição no início do XIX: "Relação do quese passou na guerracom os negros dos Palmares nos sertões dePernambuco" ${ }^{8}$ Segundo Freitas (2004, p. 19), a cópia existenteno A rquivo H istórico U Itramarino traz a indicação de ter como fonte o "tomo primeiro de Papéis Velhos de folhas cento equarentaeduas, atécento equarentaeoito, existenteno Armário deM anuscritos do Real A rquivo da Torre do Tombo". E ssa informação éa mesma que consta na cópia guardada pela Biblioteca $\mathrm{N}$ acional do Rio de Janeiro, Seção de M anuscritos, 7, 3,001, n.6.

${ }^{9} \mathrm{~N}$ ão incluo nessa lista reproduções mais recentes dos textos publicados pelo conselheiro D rummond e por Pedro Paulino da Fonseca, como as realizadas por Carneiro [(1947) 1958, p. 201-222] eSilva (1988, p. $27-44$ e 45-64).

${ }^{10} \mathrm{~A}$ primeira informação sobre o manuscrito guardado na Biblioteca $\mathrm{N}$ acional no Rio deJaneiro me foi gentilmentedada por Márcio Santos. N o A rquivo H istórico U Itramarino, contei com a preciosa ajuda de Tiago C. P. dos Reis M iranda e É rika Simone de A Imeida Carlos D ias, profundos conhecedores daquele acervo. $\mathrm{N}$ a Biblioteca $\mathrm{N}$ acional de Lisboa, meu fracasso em localizar o documento publicado por F reitas só se atenuou ao saber que M aria Lêda O liveira, coordenadora de um projeto destinado a referenciar todas as crônicas sobre o Brasil colonial nos arquivos portugueses, já completou as pesquisas na Biblioteca $\mathrm{N}$ acional de Lisboa sem tampouco conseguir localizar esse manuscrito. $\mathrm{N}$ a Torre do Tombo, minha procura também resultou infrutíferae aguardo informações da busca que vem sendo realizada por 0 dete $M$ artins, pesquisadora dessa instituição. A gradeço aqui, mais uma vez, 0 empenho e a generosidade de todos esses pesquisadores, que tanto têm me auxiliado em minhas andanças pelos arquivos portugueses.

${ }^{11}$ Cf. D ecreto de 23 de julho de 1673. Arquivo $\mathrm{N}$ acional da Torre do Tombo (AN TT), Manuscritos do Brasil, n. 33 (microf. 4114), fl. 23v. Cinco dias depois o Conselho U Itramarino pronuncia-se alertando o príncipe regente que a nomeação não havia seguido a tramitação regular. A rquivo $\mathrm{H}$ istórico U Itramarino (Projeto Resgate), AHU_ACL_CU_015,Cx.10, D. 981.

${ }^{12} \mathrm{Cf}$. Pareceres do Conselho U Itramarino de 26 de fevereiro, 28 de outubro de 1678 e 26 de novembro de 1678, todos em Biblioteca $N$ acional do Rio de Janeiro, Seção de $M$ anuscritos, Cod. II , 33, 4, 32.

${ }^{13}$ Carta dos oficiais da Câmara de 0 linda ao príncipe regente de 22 de dezembro de 1677. A rquivo H istórico U Itramarino (Projeto Resgate), AHU_ACL_CU_015, CX. 11, D. 1098. 
Os documentos textuais e as fontes do conhecimento histórico

${ }^{14} \mathrm{~A}$ residência era constituída na maior parte das vezes pela inquirição por cartas sobre eventuaisirregularidades cometidas duranteo exercício de um posto degoverno no U Itramar. Infelizmente não localizei, até agora, os papéis referentes à residência de dom Pedro de A Imeida.

${ }^{15} \mathrm{O}$ estatuto jurídico dosíndios foi objeto de muitas contendas, mas somente no século X VIII eles passaram a ser considerados vassalos plenos do monarca português. Vide, a esse respeito, D omingues (2000, p. 26-41).

(1) A guerra esteve presente em ambos os lados do A tlântico - mas com sentidos bem diferentes. $\mathrm{N}$ a A mérica, a guerra era justa contra os que permaneciam nos sertões ou dele saíam para atacar os colonos. D esde que devidamente sancionada pelas autoridades metropolitanas, podia ser feita e os índios tornavam-se legitimamente escravos. D o outro lado do A tlântico, as guerras enegociações diplomáticas estruturavam as relações entre os vários reinos centro-africanos e entre eles e os colonizadores portugueses. N os séculos XVI eXVII, em especial no caso de Angola, conquistada militarmente pelas tropas portuguesas, as relações com os reinos e sobas locais eram pontuadas por tratados eacordos de vassalagem, como meio de manter alianças militares e políticas essenciais para o domínio do território e a obtenção de escravos para o tráfico atlântico. Ver H eintze (1984).

${ }^{17}$ A naliso mais detal hadamente esse aspecto em Lara (2007).

${ }^{18}$ Retomo, assim, por outras vias, 0 argumento de Palmié (1993) que explora a hipótese de que a transferência de sistemas políticos africanos para as A méricas modelou a organização de diversos assentamentos de fugitivos no N ovo M undo, tanto no caso de Palmares como no de San Lorenzo de los N egros e outros mocambos e palenques.

\section{Referências}

A L M E IDA, M aria Regina Celestino de. M etamorfoses indígenas: identidade e cultura nas aldeias coloniais do Rio de Janeiro. Rio de Janeiro: A rquivo N acional, 2003.

AN DERSON, Robert N elson. 0 mito de Zumbi: implicações culturais para 0 Brasil e para a diáspora africana. A fro-Á sia, v. 17, p. 99-119, 1996.

BE LO, André. H istória eL ivro eL eitura. Belo H orizonte: A utêntica, 2002.

BO UZA, Fernando. Corremanuscrito. Una historia cultural del Siglo de O ro. M adrid: $M$ arcial Pons, 2001.

CARN E IRO, E dison. 0 Q uilombo dos Palmares. [1947] 2. ed. revista. São Paulo: Brasiliense, 1958. 
Sílvia Hunold Lara

CH ARTIER, Roger. Textos, impressão, leituras. In: HUNT, Lyn (O rg.). A N ova H istória C ultural. São Paulo: Companhia das Letras, 1992, p. 211-238.

DARNTON, Robert. Primeiros passos para uma história da leitura. 0 bejjo de L amourette São Paulo: Companhia das Letras, 1990, p. 146-172.

DE SCRI PÇÃ O com notícias importantes do interior de Pernambuco como rio de São F rancisco, Porto Calvo, Palmares, cabo de Santo A gostinho, as distâncias de huns lugares aos outros etcetera, das partes mais férteis; costumes dos Palmares (negros) emodo como vivem seu regimen, dos damnos que recebem os portugueses d'eles: enfim o estado em que foram achados os Palmares, sobre a partida de Pero de A Imeida contra os ditos, e a descripção do que se fez para a ruína, em que vierão a cair os Palmares. C artas de doa ção, de foral, diplomas, representaçōes, e relaçōes sobre algumas minas, a conjuração mineira, Pernambuco, B ahia, Paraíba, R io de Janeiro e M inas $G$ erais, invasão holandesa, entreoutros, 1534-1792. Biblioteca N acional do Rio deJ aneiro - Seção de M anuscritos, 7, 3, 001, fls. 73-113, doc. 6.

D O M IN G UES, Ângela. Q uando os índios eram vassalos: col onização e relaçōes de poder no $\mathrm{N}$ ortedo B rasil na segunda metade do séulo X V III. Lisboa: Comissão N acional para as Comemorações dos D escobrimentos Portugueses, 2000.

D RUM M O N D, A ntônio de M enezes Vasconcelos de. Cartas de 10 de abril de 1844 e 16 de abril de 1844. Instituto H istórico e G eográfico Brasileiro, Lata 142, pasta 6 e Lata 142, doc. 33.

DUTRA, F rancis A. M embership in the 0 rder of Christ in theSeventeenth Century: its rights, privileges, and obligations. The A mericas, v. 27, n. 1, p. 3-25, 1970.

FERRO N H A, A ntonio Luís. 0 encontro inesperado. In: FE RRO N H A, A ntonio Luís (O rg.). 0 confronto do olhar. Lisboa: E d. Caminho, 1991, p. 215-257

FO N SECA, Pedro Paulino da. Memória dos feitos que se deram durante os primeiros annos de guerra com os negros quilombolas dos Palmares, seu destroço e paz aceita em junho de 1678. R evista do Instituto H istórico e $G$ eográfico Brasilerro, v. 39, n.1, p. 293-322, 1876.

FRE ITAS, D écio. Palmares. A guerra dos escravos. [1973] 5. ed. reescrita, revistae ampliada. Porto A legre: M ercado A berto, 1984.

FREITAS, D écio. R epública dePalmares Pesquisaecomentários em documentos históricos do século XVII. Maceió: E dufal, 2004.

G ÂN D AVO, Pero de M agalhães. H istória da província Santa C ruz a que vulgarmente chamamos Brasil. [1576] Disponível em: http:// www.dominiopublico.gov.br/ download/ texto/ bn000165.pdf. A cesso em: 21 de junho de 2008.

GIUCCI, G uillermo. Sem fé, lè ou rè: Brasil 1500-1532. Rio deJaneiro: Rocco, 1993. 
Os documentos textuais e as fontes do conhecimento histórico

HE IN TZE, B eatrix. A ngola nas garras do tráfico de escravos: as guerras do N dongo (1611-1630). R evista I nternacional deE studos A fricanos, v. 1, p. 11-58, 1984.

H O BSBAW M , E ric. A história de baixo para cima. [1988] I n: Sobrea H istória. São Paulo: Companhia das Letras, 1998, p. 216-231.

LARA, Silva H unold. Marronnage et pouvoir colonial. Palmares, Cucaú et les frontières de la libertéau Pernambouc à la fin du XVII e siècle. A nnales, v. 67, n. 3, p.

@ 639-662, maio-junho 2007.

LO UREIRO, Rui. A visão do índio brasileiro nos tratados portugueses de finais do século XVI. I n:FE RRO N H A, A ntonio L uís (O rg.). 0 confronto do ol har. Lisboa: Ed. Caminho, 1991, p. 259-285.

ME LLO, JoséA ntonio G onçalves de João F ernandes V ieira, mestredecampo do T erço de Infantaria de Pernambuco. Lisboa: Comissão $\mathrm{N}$ acional para as Comemorações dos D escobrimentos Portugueses, 2000.

M O URA, Clóvis. A sinjustiças deC lio. 0 negro nahistoriografiabrasileira. Belo H orizonte: O ficina de Livros, 1990.

O LIVE IRA, Maria Lêda. A primeira R ellação do último assalto a Palmares. A froÁ sia, v. 33, p. 270-324, 2005.

PAL MIÉ, Stephan. A frican states in the N ew World? Remarks on the tradition of Transatlantic resistance. I n: BRE MER, Thomas e FLE ISCH M AN N , U Irich (E ds.), A Iternative cultures in the Caribbean. Berlin: Vervuert Verlag, 1993, p. 55-67.

PITA, Sebastião da Rocha. H istória da A mérica Portuguesa. [1730] São Paulo: E D USP/ Itatiaia, 1976.

PO M PA , Cristina. R digião como tradução: missionários, tupis e "tapuias" no Brasil colonial. Bauru: E dusc, 2003.

PO N TES, D esembargador Rodrigo de Souza da Silva. Q uaes os meios de que se deve lançar mão para obter o maior numero possível de documentos relativos à $\mathrm{H}$ istória e $\mathrm{G}$ eographia no B rasil? R evista do I nstituto H istórico e G eográfico B rasileiro, v. 3 n.10, p. 149-157, jul. 1841.

RE LAÇÃO das guerras feitas aos Palmares de Pernambuco no tempo do governador dom Pedro de Almeida de 1675 a 1678. R evista do Instituto H istórico e G eográfico B rasileiro, v. 22, p. 303-329, 1859.

[RE LAÇÃ O do que se passou na guerra com os negros dos Palmares nos sertões de Pernambuco]. Biblioteca Pública de É vora, cod. CXVI - 2 - 13 - an. 9.

RIVARA, Joaquim H eliodoro da Cunha (O rg.). C atalogo dos manuscriptos da B ibliotheca Publica E borense Lisboa: I mprensa N acional, 1850. 


\section{Sílvia Hunold Lara}

SALVAD O R, Frei Vicente do. H istoria do Brazil. [1. ed. 1627] Rio de Janeiro: Biblioteca N acional, 1889.

SI LVA, L eonardo D antas (O rg.). A lguns D ocumentos para a H istória da E scravidão. Recife: Fundaj/ M assangana, 1988.

TH ORN TON, John. E arly Kongo-Portuguese relations: a new interpretation. $\mathrm{H}$ istory in A frica, v. 8, p. 183-204, 1981.

Recebido em 19/10/2008 A provado em 10/11/2008 